\title{
O PROCESSO PRODUTIVO DO PORTAL COMUNITÁRIO: UMA EXPERIÊNCIA DE APRENDIZADO E ATENDIMENTO À COMUNIDADE
}

\author{
Cíntia Xavier ${ }^{1}$ \\ Manoel Moabis Pereira dos Anjos ${ }^{2}$ \\ Melissa Cristina Eichelbaun ${ }^{3}$
}

Resumo: Este trabalho estuda o processo produtivo do Portal Comunitário, atividade de extensão que funciona de maneira integrada com três disciplinas do terceiro ano do Curso de Jornalismo da Universidade Estadual de Ponta Grossa (Webjornalismo, Comunicação Comunitária e Telejornalismo II). O portal de notícias oferece informações sobre entidades sem fins lucrativos, sindicatos e também de movimentos sociais que atuam na cidade de Ponta Grossa. A iniciativa existe há oito anos e tem se configurado como uma experiência laboratorial muito significativa para o público envolvido.

Palavras-chave: webjornalismo, comunicação comunitária, jornal-laboratório.

\section{Introdução}

Para iniciar este relato do processo produtivo do Portal Comunitário (www.portalcomunitario.jor.br), é preciso explicar como o projeto está organizado, seja na estrutura do curso ou na distribuição dos estudantes. A proposta se desenvolve anualmente na terceira série do curso de Jornalismo da Universidade Estadual de Ponta Grossa (UEPG), e relaciona diretamente três disciplinas desta série: Webjornalismo, Comunicação Comunitária e Telejornalismo II.

O Portal Comunitário existe desde 2008, e de acordo com a própria apresentação do projeto (disponível no site): “O Portal Comunitário é uma articulação de projeto de extensão e jornal-laboratório on-line”. O portal funciona há cinco anos, e a proposta já recebeu prêmios como: Segundo lugar no Prêmio de Extensão Universitária, concedido pela Proex-UEPG (duas vezes), recebeu o primeiro lugar na categoria de JornalLaboratório Online também por dois anos consecutivos, no $14^{\circ}$ e $15^{\circ}$ Prêmio Sangue Novo do Jornalismo Paranaense, concedido pelo Sindicato dos Jornalistas do Paraná.

A proposta que norteia o processo produtivo está descrita no link "linha editoral"

\footnotetext{
${ }^{1}$ Professora do curso de graduação em Jornalismo e do Mestrado em Jornalismo da UEPG. Doutora em Ciências da Comunicação pela Unisinos.

2 Mestre em Jornalismo pela Universidade Estadual de Ponta Grossa e professor substituto em Comunicação Organizacional na UTFPR.

${ }^{3}$ Jornalista graduada pela UEPG.
} 
do próprio endereço eletrônico:

Como um serviço de informação e comunicação feito não para a comunidade, mas com a comunidade, o Portal Comunitário de Ponta Grossa tem a sua linha editorial estruturada sobre três pilares fundamentais: a comunicação comunitária, o jornalismo popular e o jornalismo alternativo.

Como jornalismo popular, o Portal Comunitário ainda informa em sua linha editorial que busca ajudar na organização e mesmo na mobilização de setores sociais. Já em relação ao jornalismo alternativo, a proposta acredita que deve destacar o valor de uso (social) da notícia. Busca o alternativo ainda como pretensão de cobertura para temas não trabalhados pelos veículos de comunicação da cidade. Já em relação à comunicação comunitária, o Portal compreende

que a comunidade não é qualquer grupo de interesse. É o sentido de pertencimento, a solidariedade, a colocação dos interesses coletivos acima dos individuais e os objetivos comuns, entre outros aspectos, que criam e mantêm a comunidade. Assim, entende que a comunidade está sempre em construção e se coloca como instrumento nesse processo.

\section{Uma produção participativa}

Em média, cerca de 30 estudantes participam da equipe de produção de notícias. Esse número é variável de acordo com a quantidade de alunos que cada ano frequentam a série. Nos primeiros encontros, ainda no início do ano, esse grupo de participantes é divido em equipes de três pessoas, mas é possível ter algumas equipes com duas ou quatro. Esta alteração acontece exatamente pela quantidade dos estudantes da turma.

Com as equipes formadas, é realizada a distribuição das entidades não governamentais, associações de moradores e sindicatos que serão atendidos naquele ano. O número de grupos assistidos também é dinâmico, uma vez que, mesmo com uma equipe de 30 pessoas, ainda não é possível dar conta de atender todos os grupos ou movimentos sociais da cidade.

A definição de participação das entidades no Portal Comunitário passa primeiro por uma relação que esses grupos mantêm com a cidade. É preciso que sejam entidades sem fins lucrativos e com certo interesse na divulgação de assuntos dos grupos para sociedade. Além de entidades, o Portal também faz cobertura das atividades de alguns sindicatos. Quase sempre, são as próprias entidades de classe que buscam participar do projeto. Além destes, alguns movimentos sociais que não estejam organizados institucionalmente também têm espaço na proposta. É o caso, por exemplo, do 
movimento pró-ciclovias (grupo de ciclistas que discute a mobilidade urbana na cidade), movimento de combate à corrupção eleitoral, entre outros.

Para completar a cobertura comunitária da cidade, o Portal Comunitário também faz matérias nos bairros da cidade. Junto à distribuição de entidades e de movimentos sociais, a cidade é dividida em regiões e cada grupo de estudantes fica com alguns bairros para cobrir. Vale ressaltar que esta variedade de grupos deve estar presente em cada equipe de trabalho no Portal, de modo que não haverá uma equipe que só faz cobertura de bairros ou ainda vai cobrir apenas sindicatos, por exemplo.

Antes de escrever matérias, os estudantes têm entre uma ou duas semanas para entrar em contato com seus respectivos grupos de cobertura e fazer um primeiro contato. Trata-se de um período de adaptação e ambientação. No caso de entidades ou de sindicatos, há uma apresentação por meio de visita destes estudantes. Já nos bairros, via associação de moradores, os estudantes são orientados a visitar o local e conversar com os moradores em uma tentativa de conhecer o local e criar um primeiro momento da relação que deve durar o ano todo. É claro que muitos buscam a experiência dos participantes do projeto no ano anterior para saber quem são as lideranças do bairro, ou mesmo se inteirar de assuntos importantes para cada região e que podem se tornar pautas.

Depois deste tempo de aproximação, os participantes do projeto realizam a reunião de pauta. O encontro é coordenado pelos professores das disciplinas que estão envolvidas na iniciativa e serve para definir o tema do que chamamos de "reportagem multimídia”. Esta produção é dividida em quatro blocos, com abordagem variada sobre um assunto, e além do texto e fotos os alunos ficam responsáveis (no segundo semestre) por fazer uma reportagem em vídeo sobre o tema. Cada equipe deve entregar uma reportagem desta modalidade por mês.

Vale destacar que durante o primeiro semestre, quando ainda não há produções audiovisuais, uma vez que o trabalho prático em Telejornalismo acontece no segundo semestre, os alunos devem oferecer um recurso em áudio para a multimídia. Isto pode ser cumprindo sem muitas complicações considerando que a disciplina de radiojornalismo, que daria suporte a essa ferramenta, já foi trabalhada com a turma no segundo ano de curso.

Além das multimídias, a cada semana, os grupos entregam uma "notícia". Tratase do desenvolvimento de uma pauta com cerca de dois mil caracteres mais foto que busca alimentar o portal ao longo do ano. A proposta é que nestas notícias os alunos possam acompanhar de maneira sistemática o dia a dia das entidades/ bairros ou movimentos que 
dão cobertura.

A produção de conteúdo para o Portal Comunitário também contempla a entrega de uma "nota" com cerca de mil caracteres sobre assunto um pouco mais factual das entidades assistidas. É nestes espaços, por exemplo, que uma assembleia de sindicato é agendada, ou ainda uma reunião na associação de moradores de determinado bairro, etc. Com essa dinâmica, o Portal Comunitário consegue manter uma atualização diária de informações sobre a cidade. Em alguns casos, há mais do que uma publicação no dia o que gera um interesse frequente de visitas ao portal na internet.

Assim que as reportagens multimídias são entregues, a equipe de produção se reúne mais uma vez para fazer a avaliação do processo produtivo. Neste dia, além de fazer considerações sobre o material publicado (multimídia, noticia ou nota), é o momento de expor o processo de produção e suas dificuldades, de sugerir mudanças ou mesmo alterações no processo produtivo.

\section{A interdisciplinaridade como elemento que garante a produção}

O trabalho interdisciplinar entre as três disciplinas (Webjornalismo, Comunicação Comunitária e Telejornalismo II) é o que possibilita manter o funcionamento do Portal Comunitário. É importante destacar ainda que além das três cadeiras diretamente envolvidas no projeto, todas pertencentes ao terceiro ano do curso, em alguns momentos as produções laboratoriais de Redação Jornalística II (segundo ano do curso) e Redação Jornalística III (terceiro ano) também oferecem conteúdo para alimentar o portal.

No caso de Redação Jornalística II, os alunos da segunda série produzem para o espaço "Notícias da Câmara", iniciativa que faz a cobertura das atividades realizadas na Câmara Municipal de Ponta Grossa. Já em Redação III, a ideia é publicar o conteúdo produzido em sala de aula. O conteúdo, que já é realizado pelos estudantes do terceiro ano nesta disciplina, passa por uma adaptação do texto (uma vez que redação III tem uma proposta de exercício de apuração e escrita para jornal impresso) e uma avaliação de validade/pertinência de publicação. Como critério para publicação ou não deste conteúdo, é levado em conta o interesse das entidades ou bairros que fazem parte do Portal Comunitário naquele assunto.

No caso de Webjornalismo, além da preocupação com toda programação técnica do Portal, a intenção é orientar os alunos quanto às especificidades do jornalismo on-line. A disciplina também busca trabalhar os principais conceitos da área através de dois encontros semanais com os estudantes divididos em três turmas: A, B e C. A divisão 
acontece porque as aulas acontecem em laboratório, e é também neste espaço de aula que são tiradas as dúvidas ou mesmo são dadas orientações quanto ao trabalho prático.

Em Comunicação Comunitária, o objetivo é acompanhar o processo de produção das notícias. A disciplina se preocupa com o processo de apuração, contato com as entidades e também com a reflexão sobre os principais conceitos de comunicação comunitária. Como não há um trabalho técnico na disciplina, os encontros semanais (no total de três) acontecem com todos os alunos sem dividi-los em turmas. Nas aulas, além da discussão sobre o trabalho de cada equipe, são usados textos que dão base à noção de Comunicação Comunitária.

Quanto à disciplina de Telejornalismo II, apesar de o professor acompanhar o projeto desde o início do ano, o trabalho "prático" no Portal só começa no segundo semestre do ano. Isso porque a cadeira está dividida em duas disciplinas na grade curricular: Telejornalismo I e Telejornalismo II. No primeiro semestre (Telejornalismo I), os alunos fazem discussões essencialmente teóricas sobre televisão e jornalismo televisivo. Já no segundo semestre, parte-se para o trabalho prático, dando suporte às pautas a serem executadas. Com a integração desta disciplina, o Portal Comunitário passa a cumprir minimamente o que se espera do jornalismo on-line, uma atenção às diferentes ferramentas de produção da notícia (texto, fotos, vídeo e áudio).

Apesar de as disciplinas trabalharem com pontos de partidas específicos, é importante destacar que há uma integração entre elas, que passa principalmente pelo debate sobre as publicações ou mesmo pela necessidade de fazer com que a proposta funcione. Um exemplo disto pode ser verificado na correção dos textos enviados pelos alunos. Apesar de a disciplina de Webjornalismo estar mais preocupada com o formato da notícia, o professor da disciplina tem autonomia para discutir pautas, enfoque e até mesmo solicitar que alguma falha na apuração seja corrigida. $O$ mesmo vale para Comunicação Comunitária, que embora esteja preocupada com o trabalho jornalístico comunitário, há abertura para sugerir formatos ou mesmo recursos de web que possam ajudar a trabalhar um determinado tema. Quanto ao trabalho em Telejornalismo II, além de dar suporte em audiovisual para as produções, há também o acompanhamento sistemático do processo produtivo.

\section{O trabalho nosso de cada semana}

O contato telefônico com os parceiros é uma estratégia desenvolvida para que as pessoas que não podem acessar o site, ou não acessam regularmente a internet, possam 
ficar sabendo que há informações, sobre o seu bairro, sindicato ou entidade, publicadas no Portal Comunitário.

Semanalmente, alunos do projeto entram em contato por telefone com as entidades parceiras do Portal. A finalidade dessas ligações é saber se a entidade tem acessado o site, se há algum evento programado para colocarmos na agenda e fazer a cobertura e também se há alguma pauta para os repórteres do Portal cobrirem. Nesse contexto, os representantes dos sindicatos, associações de moradores e movimentos sociais por muitas vezes pautam os assuntos noticiados no Portal.

A estudante Cheila Sofia Tomás Marques fala sobre a importância da participação do cidadão na notícia: "Este tipo de jornalismo depende da participação do cidadão, da colaboração, e permite um enriquecimento e democratização do trabalho do jornalista e da informação".

\section{Para além da sala de aula: o trabalho da equipe técnica}

A equipe interna do projeto é quem faz a manutenção do site. Como o terceiro ano produz apenas as matérias, o trabalho das postagens e atualização do Portal fica por conta dos estudantes que participam do que chamamos de "equipe técnica" do projeto. A postagem das notícias é dividida entre os participantes desta equipe, cada um fica responsável pela atualização em um dia da semana, e a postagem é conferida por uma bolsista que tem o cargo de "editora", para conferir se não há qualquer problema com a publicação. A editora é responsável também por orientar a hierarquia e ordem de postagem do material produzido.

As matérias também são "linkadas" com notícias que já saíram no site e que tem relação com que está sendo noticiado. Também há "linkagens" de notícias de outros sites que tenham relevância com o assunto, para que o leitor possa ter mais informações sobre o assunto.

A equipe do site atualiza várias seções do Portal. Como a seção de empregos, que é atualizada diariamente com as vagas da Agência do Trabalhador da cidade de Ponta Grossa. A seção "emprego" existe desde o lançamento do projeto. A seção "eventos da comunidade" também é atualizada pela equipe que faz o contato telefônico com as entidades, busca informações para ajudar na divulgação das atividades que os sindicatos, ONGs, movimentos e bairros realizam em Ponta Grossa.

O programa de rádio "Antena Comunitária" é produzido pela equipe interna e veiculado semanalmente com um resumo das notícias publicadas na semana. O programa 
também conta com sonoras gravadas de pessoas que são fontes das notícias produzidas pelas equipes. O objetivo do "Antena Comunitária” é oferecer mais uma oportunidade de contato com o material produzido para o portal numa plataforma diferente, como é o caso de um deficiente visual, que normalmente está impossibilitado de ler. A equipe técnica também faz a programação da ordem de entrada das notícias. De maneira organizada, após a postagem, a editora chefe vê qual matéria tem mais urgência para ser publicada, levando em conta o caráter factual destas informações e programa o dia em que esta notícia tem que entrar no Portal.

\section{Avaliação do "chão de fábrica"}

A cada ano, as equipes do portal são diferentes, por isso, a preocupação do projeto em manter uma boa relação com as entidades que os alunos cobrem. Cada entidade tem sua especificidade para a cobertura noticiosa, por exemplo, a maioria dos sindicatos tem assessor de imprensa e tem mais facilidade em enviar pautas para os repórteres. Já nos bairros a situação se inverte, os acadêmicos nem sempre encontram disponibilidade dos moradores para falar sobre os problemas relatados na matéria e há dificuldade de encontrar variedade de representantes na associação de moradores para serem fontes das matérias. Portanto, o trabalho de investigar pautas e encontrar fontes acontece mais nos bairros, já que também, nos movimentos sociais há representantes que procuram falar sobre os assuntos de maneira mais fácil.

Os repórteres escolhem as pautas levando em conta os critérios de noticiabilidade e a comunicação comunitária. Todo ano os alunos revisam o que já foi matéria no site, para não se repetir o assunto ou retomar alguma matéria para ver seu desdobramento desde sua publicação. Para a produção da notícia os repórteres vão a campo para entrevistar as fontes e também para tirar fotos que compõem a publicação no Portal.

\section{Referências}

MARQUES, Cheila Sofia Tomás. O Cidadão Jornalista: Realidade ou Ficção?, 2008.

Acesso em: Disponível em: < http://www.bocc.ubi.pt/pag/marques- cheila-cidadaojornalista-realidade-ou-ficcao.pdf >

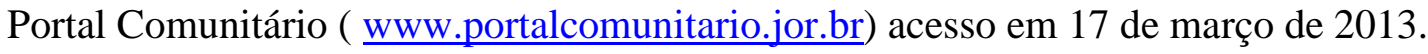

